International Journal of Theoretical and Applied Mechanics. ISSN 0973-6085 Volume 12, Number 3 (2017) pp. 589-597

\title{
Sliding Mode Control of MERS for Brightness Control of Discharge Lamps with Unity Power Factor
}

\author{
M.Vijayasanthi ${ }^{\# 1}$ and Dr. M. Sushama ${ }^{* 2}$ \\ \# EEE, CMR College of Engineering \& Technology, Secunderabad, India. \\ * EEE, JNTUH, Hyderabad, India.
}

\begin{abstract}
This paper deals with the control of charging and discharging of MERS with control on output DC voltage of the converter. The converted DC is further fed to discharge lamp with a high frequency resonant converter. The Sliding mode controller adapts the $\mathrm{Kp}$ and $\mathrm{Ki}$ gains values as per the error input and stabilizes the output DC voltage. The control and design is modeled in MATLAB software with reports and graphs.
\end{abstract}

Keywords: MERS (Magnetic Energy Recovery Switch), MATLAB (Matrix Laboratory), Kp (Proportional gain) and Ki (Integral gain)

\section{INTRODUCTION}

With wide range of applications of discharge lamps in industrial, commercial loads it is important maintain the efficiency of the lamps. Due to the high efficiency capability of the discharge lamps they generate more light intensity with less power consumption. This is an added advantage compared to incandescent bulbs or fluorescent bulbs. The efficiency of the discharge lamps are said to be in a range of 90-95\% [1] with high energy saving as compared to other bulbs. The major problem is to adjust the brightness of the discharge lamp as per the requirement. Conventional methods of varying the brightness cannot be used for the discharge lamp as the efficiency drops. This paper presents a circuit topology where the brightness is controlled and also the efficiency is maintained above $90 \%$. A resonant converter is used to generate a high frequency $\mathrm{AC}$ wave with frequency above $250 \mathrm{kHz}$ feeding the 
discharge lamp. The resonant converter converts the DC voltage from the MERS (Magnetic Energy Recovery Switch) [1] maintaining the output DC voltage constant at a particular value. The magnetic ballast technology are replaced with electronic ballast technique where the ballast operation takes place with control of power electronic switches digitally using pulse. The use of electronic ballast eliminates the problem of acoustic resonance in the circuit increasing the efficiency of the discharge lamp.

The discharge lamps are sub divided into two categories 1) florescent lamps 2) HID (High intensity Discharge lamps). As compared to fluorescent lamps the HID lamp [2] brightness is more difficult to control leaving us with only two mode either ON of OFF. This is major drawback for a high intensity ballast discharge lamp. However the brightness is very high as compared to fluorescent lamps which make these bulbs utilized at huge public areas like parks, road junctions, convention halls where illumination is required with less number of bulbs. Here another issue with the discharge lamp is that once the lamp is switched OFF it cannot be turned ON again immediately. During the operating mode the filament gets heated up to very high temperature which has to decrease once you switch OFF. After the temperature gets down to the limit the switching operation can be done. Usually this takes a time of 3045 minutes [3] which is very high delay between switching intervals. So, it is very important to control the brightness of the discharge lamp rather than switching it OFF completely. The brightness of the lamp can be lowered when there is no requirement of high intensity of light and can be immediately increase the brightness whenever it is required without any delay time. The brightness of the discharge lamp is controlled by varying the switching frequency of the resonant converter by which the amplitude of the output voltage changes. The resonant converter [4] topology with MERS can be seen below in fig. 1. When the frequency of the resonant converter changes the magnetic ballast impedance changes which in turn changes the current passing through the discharge lamp.

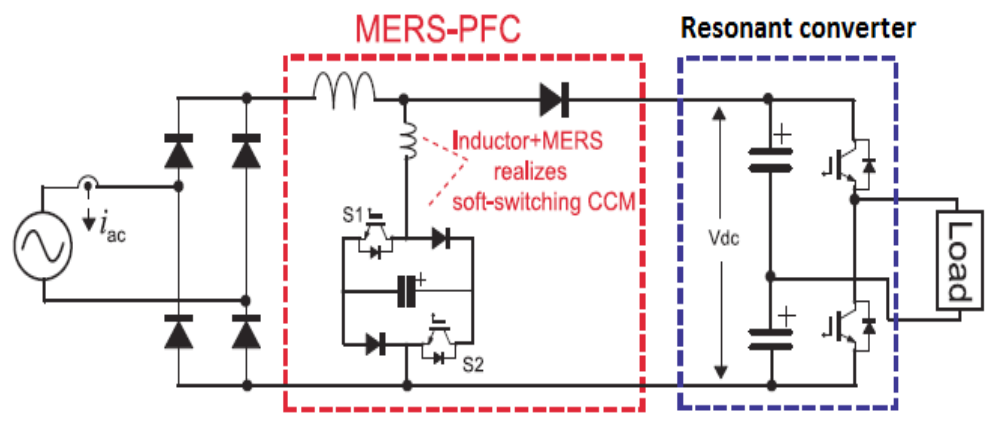

Fig. 1: Resonant converter with MERS circuit

The MERS circuit comprises of energy storage inductor and voltage stabilizing capacitor with a full bridge connected between input inductor and external diode. The MERS topology creates soft switching of the resonant converter reducing the voltage stress on the power electronic devices eliminating over shoot of voltage. The soft 
switching design of the power electronic switches increases the reliability of the proposed circuit. Also with the soft switching of the power electronic devices power factor is also controlled maintaining it at almost unity. To reduce the unstable current changes when the frequency is varying an input inductance is connected before MERS to stabilize [5] the sudden change of currents with increase or decrease of switching frequency.

A single phase AC input is fed to a diode bridge rectifier converting single phase AC to variable DC. The diode bridge DC voltage is fed to MERS with high input inductance. The MERS generates stabilized required constant DC voltage (Vdc) further converter to high frequency square wave AC [5] through a resonant converter. The high frequency $\mathrm{AC}$ is fed to a high intensity discharge lamp which can be a resistor, inductor and a capacitor in parallel. The equivalent diagram of HID lamp can be seen below in fig. 2 .

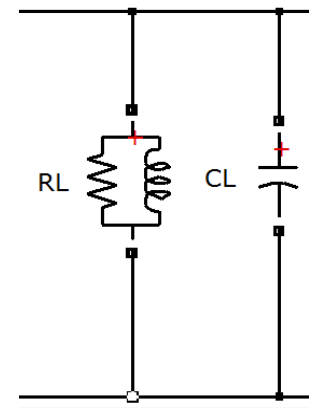

Fig. 2: HID lamp equivalent diagram

The working of the MERS topology is explained with different intervals of time in next section II.

\section{OPERARTION CHARATERISTICS OF MERS}

MERS comprises of a full H-bridge with two diodes and two power electronic devices (IGBT) with anti parallel diodes connected to them avoiding circulating currents during switching of these devices. The two power electronic switches are named as S1 and S2 with diodes D1 and D2. The DC side of the H-bridge [4] is connected to a parallel capacitor with charging and discharging control done through switching of switches S1 and S2. The two switches operate simultaneously with the same pulse signal given to both the devices. There are four modes of operations in MERS for a complete cycle of switching controlling the current direction making the capacitor to charge and discharge with respect to the given input pulse signal.

Mode I: In the first mode the capacitor is considered to be completely charged as an initial condition with both the switches S1 and S2 ON. The charge in the capacitor is discharged through the controlled switches back to the diode bridge rectifier circuit. The soft switching inductor Ls makes the current to flow through the MERS gradually increasing from zero amplitude. 


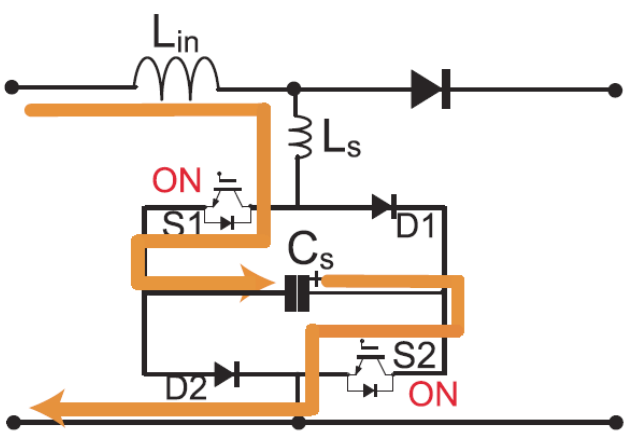

Fig. 3: Mode A operation of MERS

Mode II: This mode of operation is achieved when the capacitor is completely discharged with both the controlled switches S1 and S2 in ON state converting the circuit to a parallel conduction operation with all the power electronic switches (S1,S2, D1, D2) conducting in MERS.

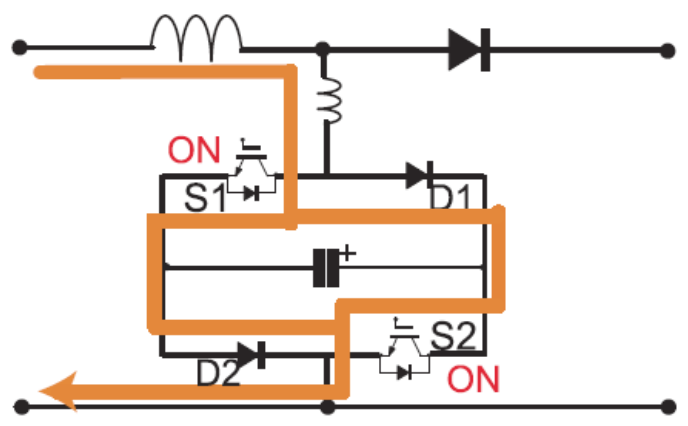

Fig. 4: Mode B operation of MERS

Mode III: At the end of mode B, the switches S1 and S2 are turned OFF to achieve mode $\mathrm{C}$ operating condition. In this mode the capacitor starts charging from zero voltage from the diode bridge rectifier through D1 and D2 freewheeling operation. This mode of operation continues until the capacitor gets charged to a voltage value slightly higher than the input voltage.

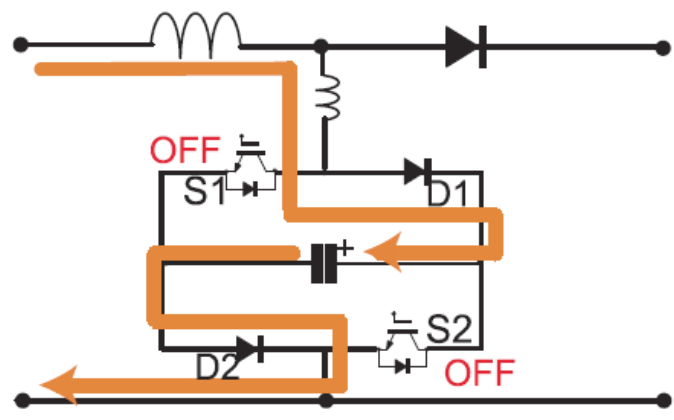

Fig. 5: Mode C operation of MERS 
Mode IV: In this operating mode when the capacitor is charged to a voltage value slightly higher than the input voltage the MERS circuit if bypassed making the external diode to conduct through resonant converter. This mode of operation continues until S1 and S2 are turned ON again for the next cycle.

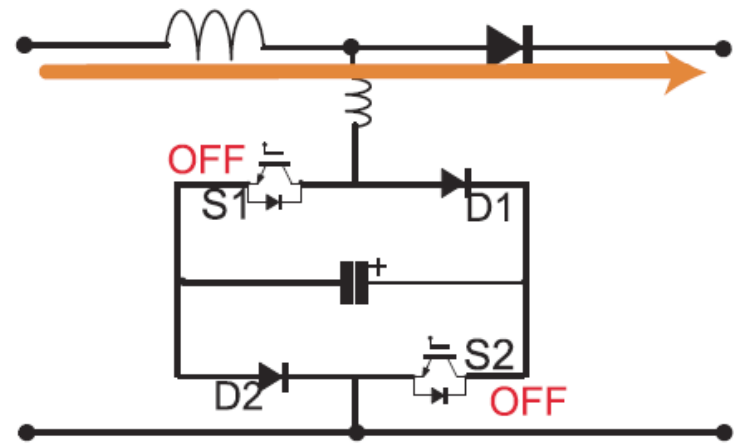

Fig. 6: Mode D operation of MERS

\section{INTEGRATION OF SLIDING MODE CONTROL INTO MERS}

As it can be observed in the above section II the control of the switching times of S1 and S2 changes the state of operation of MERS. The duty ratio of switches S1 and S2 are be controlled with a feedback system with reference inputs of Iac (input AC current) and Vdc (DC voltage) after MERS. The conventional feedback control loop contain PI controller with specific $\mathrm{Kp}$ (Proportional gain) and Ki (Integral gain) values which are given as default, generating a dynamic duty ratio (D) [6] with respect to change in Iac and Vdc values comparison. The conventional feedback loop control of duty ratio with PI controller can be seen below in fig. 7 .

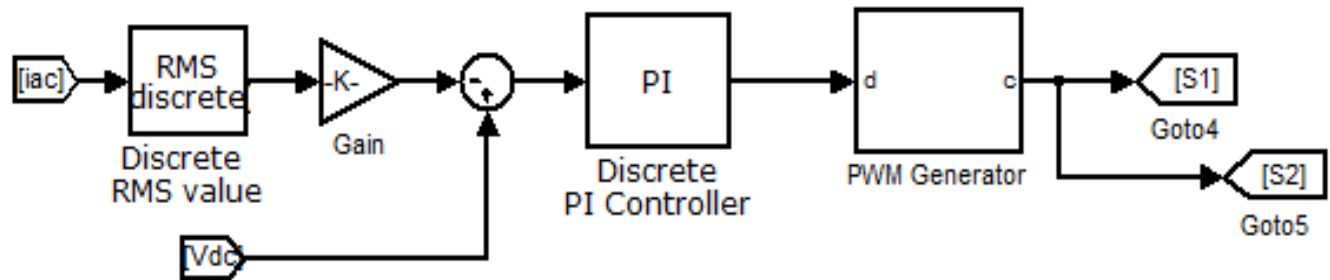

Fig. 7: PI feedback loop control of MERS

In the above mentioned method of generating dynamic duty ratio the controller gains doesn't adapt to the error input from the comparator. With this non adapting issue the controller reaction time is decreased with increase in DC voltage (Vdc) settle time [7]. The output DC voltage settles to its stabilized amplitude value after a long time of operation of the circuit topology. This leads to failure in constant high frequency AC wave damaging the HID lamp. The conventional PI controller is replaced with Sliding mode controller [8] in which the $\mathrm{Kp}$ and $\mathrm{Ki}$ values change with respect to change in error value. The values of $\mathrm{Kp}$ and $\mathrm{Ki}$ are varied exponentially, as high values for high 
error input and low values for low error input. The Sliding mode control of the new feedback control loop can be seen below in fig, 8 .

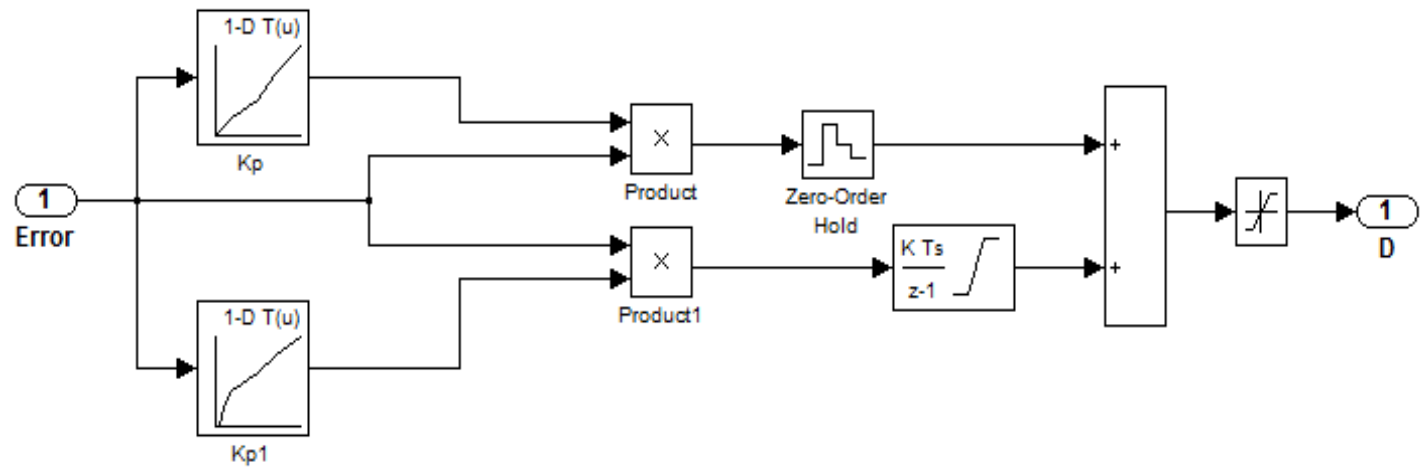

Fig. 8: Sliding mode controller

As it can be observed in the fig. 8 the $\mathrm{Kp}$ and $\mathrm{Ki}$ values are generated exponentially with input of error signal. The values are adjusted with the help of a single dimension characteristic table with specific input breakpoints and output values. The $\mathrm{Kp}$ is multiplied directly with the error signal [8] and $\mathrm{Ki}$ is multiplied and fed to an integrator. Both the values are added to generated the dynamic duty ratio fed to a high frequency triangular waveform generating a pulses given to S1 and S2. The values of $\mathrm{Kp}$ and $\mathrm{Ki}$ are dynamic with respect to input error making the MERS to react faster to the change decreasing he settling time of the DC voltage (Vdc).

\section{SIMULINK MODELING AND RESULTS}

The total schematic of MERS with HID lamp and also the sliding mode controller are modeled in MATLAB simulink environment with GUI tool the graphs of input voltage, input current, output voltage output current are given. Along with these results a comparison of output DC voltage of MERS with PI and Sliding mode control is also given.

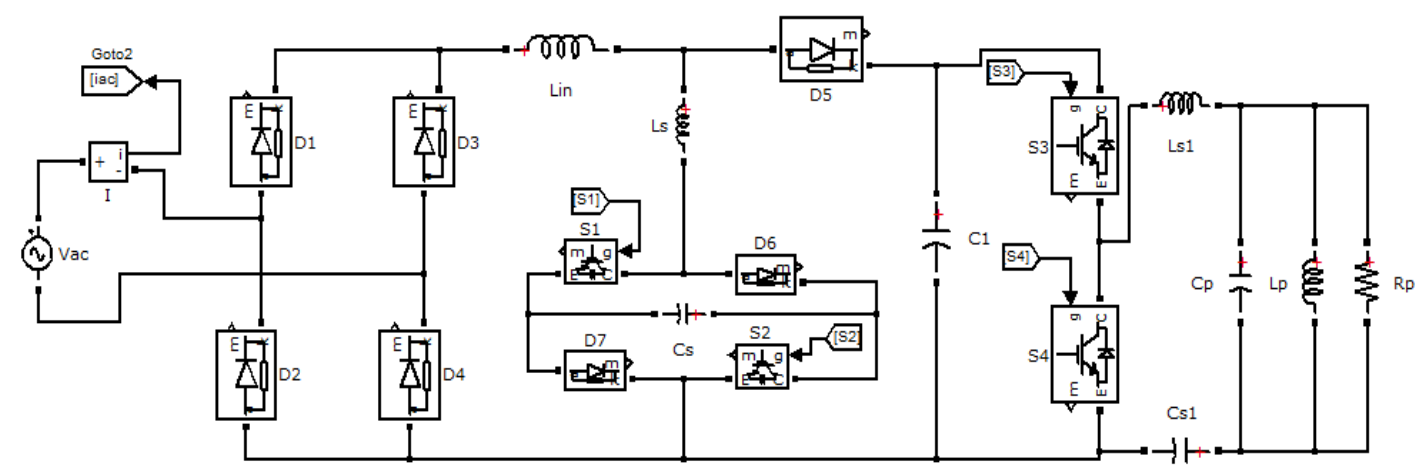

Fig. 9: Simulink model of proposed topology 


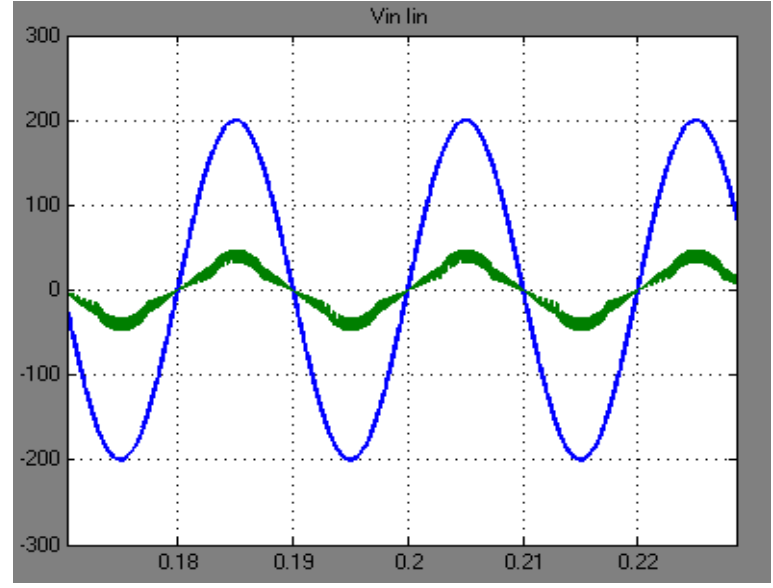

Fig. 11: Input voltage and input current

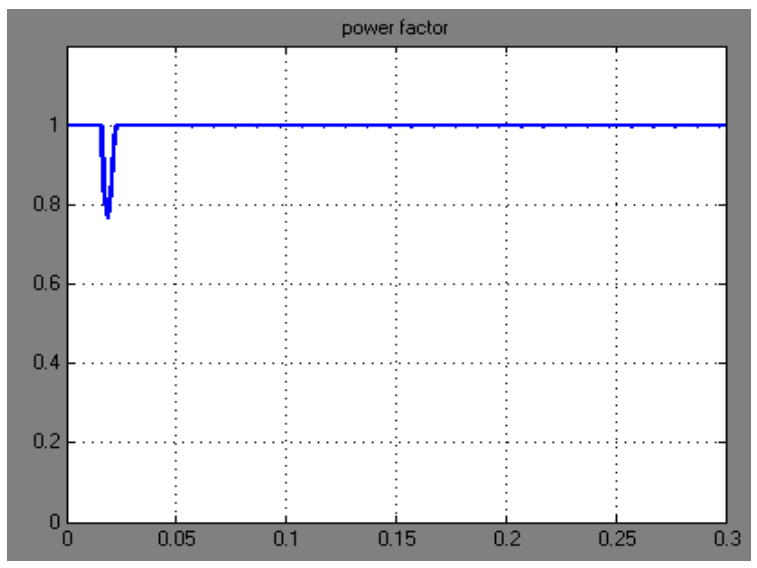

Fig. 12: Input power factor

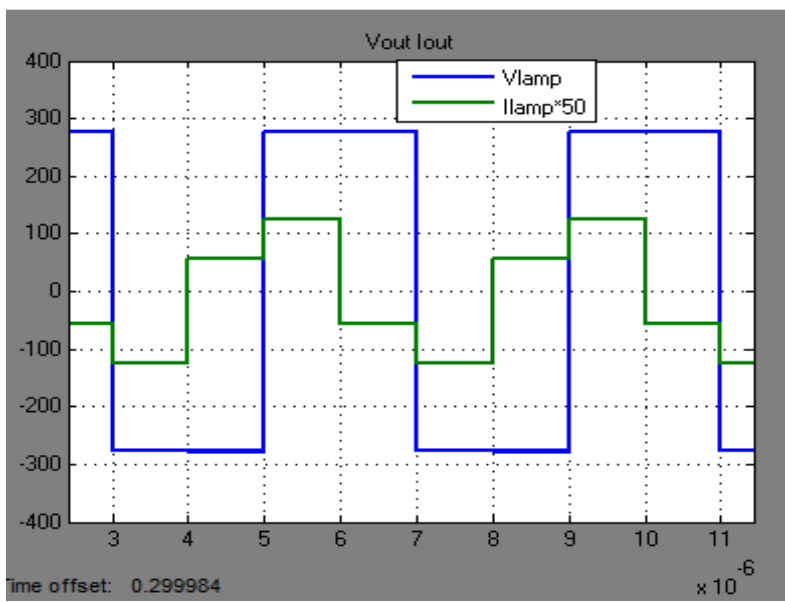

Fig. 13: Ballast lamp voltage and current 


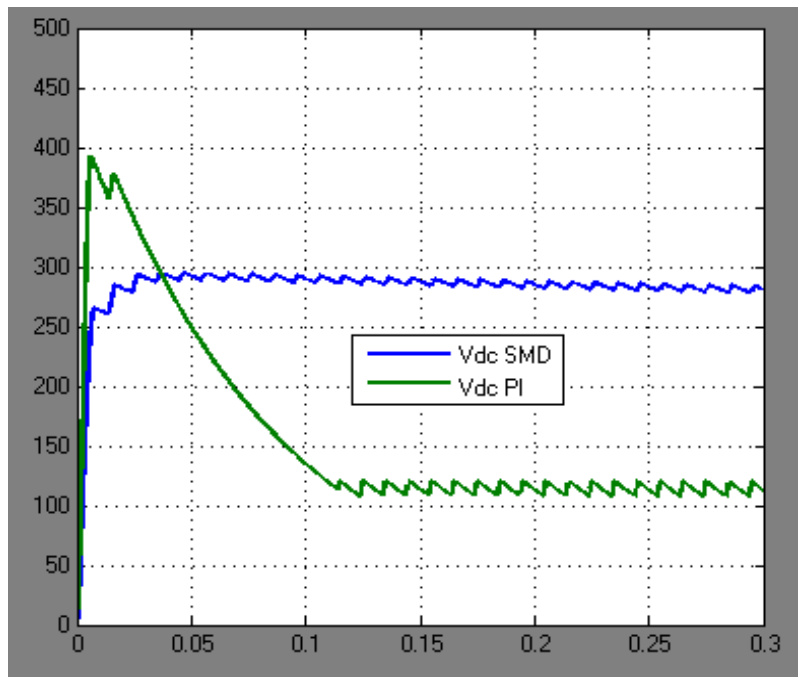

Fig. 14: Comparison of Vdc values with PI and Sliding mode control

\section{CONCLUSION}

With the above results it is clear that DC output voltage (Vdc) of MERS is stabilized fast for Sliding mode controller as compared to PI controller. Even the output voltage amplitude is increased with increased duty ratio and ripple content is also less for the sliding mode controller. The adapting of $\mathrm{Kp}$ and $\mathrm{Ki}$ values of the controller with respect to the change in error improves the response time of the circuit topology and stabilizes the DC voltage faster as compared to any other controller.

\section{REFERENCES}

[1] Chien-Ming Wang; "A Novel Single-Stage High-Power-Factor Electronic Ballast With Symmetrical Half-Bridge Topology" Industrial Electronics, IEEE Transactions on , vol.55, no.2, pp.969-972, Feb. 2008.

[2] Tae-Eun Jang; Hee-Jun Kim; Hoon Kim; , "Dimming Control Characteristics of Electrode less Fluorescent Lamps" Industrial Electronics, IEEE Transactions on , vol.56, no.1, pp.93-100, Jan. 2009.

[3] S. Y. Ron Hui, Leung Ming Lee, Henry Shu-Hung Chung, Y. K. Ho. "An electronic ballast with wide dimming range, high PF, and low EMI", IEEE Transactions on Power Electronics, vol. 16, n.4, pp. 465-472, Jul. 2001.

[4] M.C.Cosby and R.M.Nelms, "A resonant inverter for electronic ballast applications," IEEE Transaction on Industrial Electronics, vol. 41, no. 4, pp. 418-425, 2011. 
[5] J. L. Freitas Vieira, M. A. Co, and L. D. Zorzal, "High power factor electronic ballast based on a single power processing stage," in IEEE PESC'95, 2005, pp. 687-693.

[6] S. Z. Chen, N. C. Cheung, K. C. Woong, and J. Wu, "Integral sliding-mode direct torque control of doubly-fed induction generators under unbalanced grid voltage," IEEE Trans. Energy Convers., vol. 25, no. 2, pp. 356-367, Jun. 2010 .

[7] V. I. Utkin, "Sliding mode control design principles and applications to electric drives," IEEE Trans. Ind. Electron., vol. 40, no. 1, pp. 23-26, Feb. 1993.

[8] M. Carpita and M. Marchesoni, -Experimental study of a power conditioning system using sliding mode control,॥ IEEE Trans. Power Electron.,vol. 11, no. 5, pp. 731-742, Sep. 1996. 
